\title{
PARENTERAL NUTRITION IN VERY LOW BIRTH WEIGHT INFANTS. WHEN TO START?
}

\author{
Maria Amenaide Carvalho Alves de Sousa \\ Assistent Professor, Medicine and \\ Public Health, Salvador, Bahia, Brazil. \\ Neonatologist - Neonatal Intensive Care - \\ NEOCENTRO - Hospital Santo Amaro, Salvador, \\ Bahia, Brazil. \\ Ana Suely Vieira \\ Assistent Professor, Medicine and \\ Public Health, Salvador, Bahia, Brazil. \\ Neonatologist - Neonatal Intensive Care - \\ NEOCENTRO - Hospital Santo Amaro, Salvador, \\ Bahia, Brazil. \\ Suely Ribeiro Neonatologist - Neonatal Intensive Care - \\ NEOCENTRO - Hospital Santo Amaro, Salvador, \\ Bahia, Brazil. \\ Lícia Maria Oliveira Moreira \\ Neonatologist - Neonatal Intensive Care - \\ NEOCENTRO - Hospital Santo Amaro, Salvador, \\ Bahia, Brazil. Full Professor, Pediatric Departament. \\ Universidade Federal da Bahia, Salvador, Bahia, \\ Brazil.
}

\begin{abstract}
Objective: To assess the effects of parenteral nutrition (PN) initiation time in very low birth weight neonates on: the birth weight recovery time, enteral nutrition (EN) initiation time, duration of hospitalization, and incidence of death. Methods: This retrospective case-control study was performed in the neonatal intensive care unit (NICU) of a tertiary center: Santo Amaro Hospital, Salvador, Brazil. All infants with birth weights $\leq 1500 \mathrm{~g}$ who were treated in the NICU during the study period $(n=114)$ were included. The sample was divided in two groups: early ( $\leq 48 \mathrm{~h}$ after birth) and late $(>48 \mathrm{~h}$ after birth) onset of PN. We also analyzed a subgroup of neonates with birth weights $\leq 750 \mathrm{~g}$, as well as a group for whom PN was initiated very early ( $\leq 24 \mathrm{~h}$ after birth). Results: A total of 114 neonates ( $n=48 / 39.8 \%$ in early PN group), were included in the study. Birth weight recovery time $(9.9 \pm 4.0$ vs $12.8 \pm 6.1, \mathrm{p}=0.007)$, lenght of hospitalization $(43.2 \pm 4.0$ vs $71.8 \pm 41.7, \mathrm{p}=0.007)$, and time of EN onset $(2.2 \pm 1.2$ vs $7.9 \pm 5.8, \mathrm{p}<0.001)$, were significantly lower in the early PN onset group than in the late onset group. Lenght of hospitalization was positively correlated with the timing of EN onset $(r=0,37, p=0,001)$. No significant difference in adverse outcomes: death $(18.6 \%$ vs $13.6 \%, \mathrm{p}=0.6)$, intracranial hemorrhage (ICH) $(8.3 \%$ vs $12.1 \%, \mathrm{p}=0.9)$ and patent ductus arteriosus (PDA) $(8.3 \%$ vs $31.8 \%, \mathrm{p}=0.1)$ was obbserved between groups. Conclusion: In this study, the early initiation of nutritional support in very low birth weight neonates can reduce the length of hospitalization thereby reducing costs, without increasing the incidence of adverse effects.
\end{abstract}

Keywords: Very low birth weight; Premature infant; Parenteral nutrition; Enteral nutrition.

\section{INTRODUCTION}

Prematurity is the leading cause of neonatal morbidity and mortality, ${ }^{(1)}$ and premature neonates, have greater nutrient and energy requirements than infants born at term. Neonatal nutrition remains a critical issue for neonatologists, as many high-risk premature infants 
receive insufficient amounts of enteral nutrition (EN) or receive only parenteral nutrition $(\mathrm{PN})$, which frequently leads to growth restriction. ${ }^{(2)}$

Nutritional support is provided to preterm infants with the aims of: reducing mortality, length of hospitalization and infectious processes, as well as maintaining gastrointestinal function and modulating the inflammatory response. ${ }^{(3,4)}$ Deferring nutritional therapy, with the expectation of neonatal stability, ignores the consequences of failure to begin nutritional support immediately after birth; the newborn enters a state of catabolism that does not contribute to clinical stability, development or growth. ${ }^{(3-5)}$ Therefore, the medical team must recognize that premature birth is a nutritional emergency and every effort should be made to reduce nutritional deficits. ${ }^{(5,6)}$

The objective of this study was to assess the effects of PN initiation time in very low birth weight neonates on: the birth weight recovery time, EN initiation time, duration of hospitalization, and incidence of death.

\section{MATERIAL AND METHODS}

This retrospective case-control study was performed in the neonatal intensive care unit (NICU) of a tertiary Center: Santo Amaro Hospital, Salvador, Brazil.

Data were obtained from the medical records of all preterm infants born between January and December 2007. All infants with birth weights $\leq 1500 \mathrm{~g}$ who were treated in the NICU during that period $(n=114)$ were included in the study. Neonates with congenital anomalies or birth asphyxia, and those who were transferred to another hospital or for whom data were missing, were excluded.

The sample was divided in two groups: early ( $\leq 48 \mathrm{~h}$ after birth) and late ( $>48 \mathrm{~h}$ after birth) onset of PN. We also analyzed a subgroup of neonates with birth weights $\leq 750 \mathrm{~g}$, as well as a group for whom PN was initiated very early ( $\leq 24 \mathrm{~h}$ after birth).

The following demographic variables were obtained: birth weight, gestational age, mode of delivery, and APGAR score. ${ }^{(7)}$ Weight was recorded daily and the percentage of weigth loss was determined. 
We analyzed the following respiratory outcomes: duration of intermittent mandatory ventilation (IMV), continuous positive airway pressure (CPAP) and duration of oxygen therapy.

Nutritional outcomes included in the analysis were PN and EN initiation times, birth weight recovery time, enteral and parenteral fluid and calorie rates on 10th day of life. Enteral and parenteral fluid and calorie rates were recorded daily for the duration of the study protocol.

The following adverse outcomes were considered: death, intracranial hemorrhage (ICH), patent ductus arteriosus (PDA) and length of hospitalization.

PDA was diagnosed by a pediatric cardiologist using two-dimensional echo imaging. Cranial ultrasound examinations were conducted by an experienced neonatologist.

Statistical analysis: Variables were characterized using means and standard deviations. Before the analysis, symmetry and kurtosis testing were performed to identify the normality of the data and the assumptions of the analysis. Means were compared by Student's t test for independent samples. All analyses were performed using SPSS software (Statistical Package for Social Sciences) version 13.0; (SPSS Inc., Chicago, IL USA.) with a significance level of $5 \%$.

Ethical aspects: This study was performed according to the guidelines on human research of the Declaration of Helsinki and Resolution 196/96 of the National Health Council. All study protocols were approved by the Institutional Ethics Committee.

\section{RESULTS}

A total of 114 neonates ( $n=48 / 39.8 \%$ in early PN group), were included in the study. Mean birth weight was $1103.8 \pm 246.8 \mathrm{~g}$ and mean gestational age was $29 \pm 1$ weeks. The groups did not differ in term of birth weight $(1185,8 \pm 227,4$ vs $1081,8 \pm 253,4 \mathrm{~g}$; $\mathrm{p}=0,16)$, Apgar score $(8,1 \pm 1,2$ vs $8,1 \pm 1,2 ; p=0,95)$. Birth weight recovery time (9.9 \pm 4.0 vs $12.8 \pm$ $6.1, \mathrm{p}=0.007)$, lenght of hospitalization $(43.2 \pm 4.0$ vs $71.8 \pm 41.7, \mathrm{p}=0.007)$, and time of EN onset $(2.2 \pm 1.2$ vs $7.9 \pm 5.8, p<0.001)$, were significantly lower in the early PN onset group than in the late onset group. Lenght of hospitalization was positively correlated with the 
timing of EN onset $(r=0,37, p=0,001)$. The early PN onset group had a significantly greater enteral fluid intake on the 10 th day of life $(91.5 \pm 61.1$ vs $31.0 \pm 39.6, \mathrm{p}<0.001$; Table 1$)$.

Table 1 - Comparison between early and late onset of parenteral nutrition in neonates with birth weight $\leq 1500 \mathrm{~g}$

\begin{tabular}{|c|c|c|c|}
\hline & $\begin{array}{c}\text { EARLY PARENTERAL } \\
\text { NUTRITION } \\
48(39,8 \%) \\
\end{array}$ & $\begin{array}{c}\text { LATE PARENTERAL } \\
\text { NUTRITION } \\
66(60,6 \%) \\
\end{array}$ & $\mathbf{p}$ \\
\hline \multicolumn{4}{|c|}{ NUTRITIONAL OUTCOMES } \\
\hline Initiation of parenteral nutrition (days) & $2,0 \pm 0,6$ & $2,6 \pm 1,1$ & 0,010 \\
\hline Initiation of enteral nutrition(days) & $2,2 \pm 1,2$ & $7,9 \pm 5,8$ & 0,000 \\
\hline Total fluid rate $1^{\circ} \mathrm{d}(\mathrm{ml} / \mathrm{kg})$ & $60,0 \pm 28,6$ & $61,6 \pm 36,0$ & 0,796 \\
\hline Total Calorie rate $1^{\circ} \mathrm{d}(\mathrm{cal} / \mathrm{kg})$ & $6,4 \pm 14,8$ & $3,2 \pm 11,2$ & 0,204 \\
\hline Enteral fluid rate $10^{\circ} \mathrm{d}(\mathrm{ml} / \mathrm{kg})$ & $91,5 \pm 61,1$ & $31,0 \pm 39,6$ & 0,000 \\
\hline Enteral calorie rate $10^{\circ} \mathrm{d}(\mathrm{cal} / \mathrm{kg})$ & $64,1 \pm 42,8$ & $27,5 \pm 45,6$ & 0,000 \\
\hline Parenteral fluid rate $10^{\circ} \mathrm{d}(\mathrm{ml} / \mathrm{kg})$ & $69,9 \pm 61,4$ & $116,8 \pm 44,2$ & 0,000 \\
\hline Parenteral calorie rate $10^{\circ} \mathrm{d}(\mathrm{cal} / \mathrm{kg})$ & $32,4 \pm 37,1$ & $64,8 \pm 32,6$ & 0,000 \\
\hline Total fluid rate $10^{\circ} \mathrm{d}(\mathrm{ml} / \mathrm{kg})$ & $159,5 \pm 29,0$ & $168,6 \pm 157,1$ & 0,707 \\
\hline Total calorie rate $10^{\circ} \mathrm{d}(\mathrm{cal} / \mathrm{kg})$ & $97,6 \pm 25,8$ & $64,8 \pm 32,6$ & 0,050 \\
\hline Birth weight recovery time (days) & $9,9 \pm 4,0$ & $12,8 \pm 6,1$ & 0,007 \\
\hline Hospitalization time (days) & $43,2 \pm 4,0$ & $71,8 \pm 41,7$ & 0,007 \\
\hline \multicolumn{4}{|c|}{ VENTILATORY OUTCOMES } \\
\hline IMV time (days) & $6,9 \pm 12,2$ & $8,9 \pm 16,8$ & 0,492 \\
\hline CPAP time (days) & $4,6 \pm 6,9$ & $5,2 \pm 7,6$ & 0,688 \\
\hline $\mathrm{O}_{2}$ time (days) & $13,0 \pm 15,6$ & $15,5 \pm 21,3$ & 0,487 \\
\hline
\end{tabular}

Parenteral nutrition (PN); Intermitent Mandatory Ventilation (IMV); continuous positive airway pressure (CPAP).

No significant difference in adverse outcomes: death (18.6\% vs $13.6 \%, \mathrm{p}=0.6$ ), intracranial hemorrhage $(\mathrm{ICH})(8.3 \%$ vs $12.1 \%, \mathrm{p}=0.9)$ and patent ductus arteriosus (PDA) $(8.3 \%$ vs $31.8 \%, p=0.1)$ was obbserved between groups (Table 2$)$.

Table 2 - Adverse outcomes

\begin{tabular}{|c|c|c|c|}
\hline & $\begin{array}{c}\text { EARLY PARENTERAL NUTRITION } \\
48(39,8 \%)\end{array}$ & $\begin{array}{c}\text { LATE PARENTERAL } \\
\text { NUTRITION } \\
66(60,6 \%)\end{array}$ & $\mathbf{p}$ \\
\hline Death & $8(18,6 \%)$ & $9(13,6 \%)$ & 0,59 \\
\hline Intracranial hemorrhage & $4(8,3 \%)$ & $8(12,1 \%)$ & 0,90 \\
\hline Patent ductus arteriosus & $4(8,3 \%)$ & $21(31,8 \%)$ & 0,10 \\
\hline
\end{tabular}

In the subgroup analysis of neonates with birth weights $\leq 750 \mathrm{~g}$, no significant difference was found between the early and late onset groups (Table 3). 
Table 3 - Comparison between early and late onset of parenteral nutrition in neonates with birth weight $\leq 750 \mathrm{~g}$

\begin{tabular}{lccc}
\hline & $\begin{array}{c}\text { EARLY PARENTERAL } \\
\text { NUTRITION }\end{array}$ & $\begin{array}{c}\text { LATE PARENTERAL } \\
\text { NUTRITION }\end{array}$ & p \\
\hline Birth weight (g) & $657,1 \pm 77,0$ & $649,0 \pm 78,3$ & 0,861 \\
IMV time (days) & $16,7 \pm 13,5$ & $28,2 \pm 19,1$ & 0,247 \\
CPAP time (days) & $11,3 \pm 13,6$ & $8,0 \pm 6,2$ & 0,587 \\
O $_{2}$ time (days) & $28,1 \pm 14,7$ & $43,0 \pm 29,5$ & 0,343 \\
Hospitalization time (days) & $54,9 \pm 33,1$ & $104,6 \pm 89,0$ & 0,199 \\
Birth Weigth recovery time (days) & $11,1 \pm 3,8$ & $8,0 \pm 7,0$ & 0,335 \\
Start enteral (days) & $4,0 \pm 4,2$ & $8,0 \pm 5,1$ & 0,165 \\
\hline
\end{tabular}

Intermitent Mandatory Ventilation (IMV); continuous positive airway pressure (CPAP).

PN initiation in the first $24 \mathrm{~h}$ of life, significantly reduced the duration of IMV $(3.7 \pm$ 5.4 vs $15.6 \pm 8.6, p=0.033$ ), a variable that showed no difference between groups in which $\mathrm{PN}$ was initiated $\leq 48 \mathrm{~h}$ or $>48 \mathrm{~h}$ after birth $(6,9 \pm 12,2$ vs $8,9 \pm 16,8, \mathrm{p}=0,49)$.

Birth weight recovery time $(12,6$ vs 10,5; $\mathrm{p}=0,05)$ and the time of $\mathrm{EN}$ onset $(7,2$ vs 4,4; $p=0,01)$ were significantly longer in preterm infants of preeclamptic mothers.

\section{DISCUSSION}

In this sample of preterm infants PN onset in the first $48 \mathrm{~h}$ of life, reduced the timing of EN initiation, and progression to full EN, birth weight recovery time, and lenght of hospitalization. No increase in adverse outcomes such as death, ICH and PDA was observed. We found no difference between early and late PN onset in premature infants with birth weights $\leq 750 \mathrm{~g}$, but this group is at high risk.

Garcia et al. ${ }^{(8)}$ obtained similar results in a sample of 58 premature infants weighing $<1500 \mathrm{~g}$; the early PN onset group regained birth weight sooner and had shorter hospital stays, and showed no increase in cases of PDA, death or IMV duration. These findings are particularly important in very low birth weight premature neonates, who are expected to undergo greater weight loss and require a longer time to recover birth weight than are fullterm infants. ${ }^{(5)}$ In premature infants, the combination of reduced nutrient supply with high demands and losses, leads to a catabolic state. ${ }^{(3,4)}$ The early initiation of nutritional support reverses the catabolic state and helps to achieve clinical stability. ${ }^{(3-6,10)}$ In our early PN onset group, EN onset and full EN occurred sooner and calorice intake on the 10th day of life was greater than in late onset group. The early initiation of EN, in the first week of life, is important in maintaining the intestinal barrier and preventing bacterial 
translocation; it has a trophic effect on the maintenance of the intestinal mucosa and leads to an attenuation of the metabolic response. ${ }^{(2,3,6,9,10)}$ The reduction in time to reach total EN reduces the risk of infection by venous colonization and decreases the time needed to achieve total EN independent of PN. ${ }^{(6,9)}$ Although the early and late PN onset groups showed no difference in the duration of ventilatory suport, IMV was reduced in the subgroup that began nutritional support in the first $24 \mathrm{~h}$ after birth. This finding was in accordance with Wenhomer et al. ${ }^{(11)}$ who showed that very low birth weight premature infants who developed bronchopulmonary dysplasia (BPD) had lower EN intake. BPD is an important cause of longterm ventilatory support.

Especially in very low birth weight neonates PDA and ICH are related to the rate of fluids and also can lead to increased mortality. ${ }^{(12)}$ In this sample, we found no increase in adverse events in the early PN onset group.

The early PN onset group showed reductions in birth weight recovery time and lenght of hospitalization, two important clinical and economic outcomes. The reduction in the lenght of hospitalization, has a strong psychological impact on the family and on public health spending. A recent study performed in Brazil showed that the average cost of a premature infant's stay in the intensive care unit for a day was USD 96 per day. ${ }^{(13)}$ Premature infants with the lowest birth weights incurred the highest daily costs, ${ }^{(13)}$ thus, the reduction of hospital stays is economically important.

The findings of this study indicate that the early initiation of nutritional support in very low birth weight neonates can reduce the length of hospitalization thereby reducing costs, without increasing the incidence of adverse effects.

\section{REFERENCES}

1. Rüegger C, Heggelin M, Adams M, Bucher HU. Population based trends in mortality, morbidity and treatment for very preterm and very low birth weight infants over 12 years. BMC Pediatr.2012;12:17.

2. Ben XM. Nutritional management of newborn infants: pratical guidelines. World $J$ Gastroenterol.2008; 14 (40): 6133-9. 
3. Delgado AF, Feferbaum R, Vaz FAC. Bases da Nutrição do Recém-nascido Doente. In: Feferbaum R, Falcão MC. (organizador). Nutrição do Recém-nascido. São Paulo: Atheneu; 2003. v. 1, p. 361-370.

4. Hay Júnior, WW. Strategies for feeding the preterm infant Neonatology 2008; 94:245-54.

5. Corpeleijn WE, Vermeulen MJ, van den Akker CH, van Goudoever JB. Feeding verylow-birth-weight infants: our aspirations versus the reality in pratice. Ann Nutr Metab.

2011;58 (1): 20-9.

6. Senterre T, Rigo J. Reduction in posnatal cumulative nutritional déficit and improvement of growth in extremely preterms infants. Acta Paediatr. 2012; 101(2):e64-70

7. Apgar V. A proposal for a new method of evaluation of the newborn infant. Curr. Res. Anesth. Analg. 1953; 32 (4): 260-7.

8. García LV, Erroz IO, Freire MM, Muñuzuri AP, Souto AB, Pico ML et al. Does early parenteral protein intake improve extrauterine growth in low birth weight preterms? An Pediatr (Barc). 2012;76(3):127-132.

9. Civardi E, Tzialla C, Garofoli F, Mazzucchelli I, Bollani L, Stronati M. Nutritional needs of premature infants. J Matern Fetal Neonatal Med. 2011; 24 (1): 27-9.

10. Morgan J, Young L, McGuire W. Delayed introduction of progressive enteral feeds to prevent necrotising enterocolitis in very low birth weight infants. Cochrane Database Syst Ver. 2011; (3):CD001970.

11. Wemhöner A, Ortner D, Tschirch E, Strasak A, Rüdiger M. Nutrition of preterm infants in relation to bronchopulmonary dysplasia. BMC Pulm Med. 2011;11:7.

12. Fanos V, Pusceddu M, Dessì A, Marcialis MA. Should we definitively abandon prophylaxis for patent ductus arteriosus in preterm new-borns? Clinics.2011; 66:(12): 21412149.

13. Desgualdo CM, Riera R, Zucchi P. Cost estimate of hospital stays for premature newborns in a public tertiary hospital in Brazil. Clinics. 2011;66(10):1773-1777. 